\title{
PSICOMOTRICIDADE RELACIONAL SOB A ÓTICA DE CONCEITOS TEÓRICOS DE VYGOTSKY E BRONFENBRENNER
}

\author{
Ângela Adriane Schmidt Bersch (FURG)* \\ https://orcid.org/0000-0002-1263-9309 \\ Maria Angela Mattar Yunes (Universidade Salgado de Oliveira)** \\ https://orcid.org/0000-0002-4653-3895 \\ Susana Inês Molon (FURG)*** \\ https://orcid.org/0000.0001-8440-4579
}

\section{RESUMO}

O presente artigo tem por objetivo apresentar a Psicomotricidade Relacional (PR) por meio do diálogo entre a teoria sócio-histórica de Lev Semionovitch Vygotsky e a teoria Bioecológica de Urie Bronfenbrenner. A PR tem por base os aspectos lúdicos do brincar com movimento e expressões corporal/artística/ musical/verbal. Essas são as linguagens através das quais as crianças se manifestam e se comunicam, estabelecendo pontes entre o real e o imaginário. As relações na PR serão a tônica do diálogo conceitual estabelecido entre os autores, enfatizando-se o poder das díades em Bronfenbrenner e os processos de mediação semiótica em Vygotsky. Lançar o "olhar" sob o prisma destas duas teorias permite ressaltar a relevância do papel do psicomotricista como propulsor de interações de desenvolvimento com os participantes. A PR potencializa, por meio das relações, a criatividade, a busca da autonomia e uma compreensão maior de si mesmo, e pode projetar mudança de atitudes. Conclui-se que a PR representa um diferencial no que se refere à sua metodologia potencializadora de novas aprendizagens.

Palavras-chave: Psicomotricidade relacional. Bioecologia. Mediação semiótica.

\section{ABSTRACT}

\section{RELATIONAL PSYCHOMOTRICITY FROM THE PERSPECTIVE OF THEORETICAL CONCEPTS OF VYGOTSKY AND BRONFENBRENNER}

This article aims to present Relational Psychomotricity (RP) through a dialogue between the socio-historical theory of Lev Semionovitch Vygotsky and the

* Doutora em Educação Ambiental pela Universidade Federal do Rio Grande (FURG). Professora do Instituto de Educação da Universidade Federal de Rio Grande (IE/FURG).E-mail: angelabersch@gmail.com

** Pós-Doutorado em Psicologia do Desenvolvimento pela Universidade Federal do Rio Grande do Sul (UFRGS). Professora permanente na Universidade Salgado de Oliveira (UNIVERSO). Colaboradora no Programa de Pós-Graduação em Educação da Universidade La Salle (UNILASALLE) - Canoas, RS. E-mail: mamyunes@yahoo.com.br

*** Pós-doutorado em Educação pela Universidade Estadual de Campinas (UNICAMP). Docente titular aposentada da Universidade Federal do Rio Grande (FURG). E-mail: susanamolon@vetorial.net 
Bioecological theory of Urie Bronfenbrenner. The RP is based on playful aspects of movement and its expressions in the body/art/ music/ verbal. These are languages through which children show and communicate making bridges between reality and fantasy. Relationships are the keynote of the conceptual dialogue established between the two authors with emphasis in the power of dyads in Bronfenbrenner and the semiotic mediation processes in Vygotsky. This "look" at RP in the light of these two theories allows to confirm the relevance of the role of the psychomotricist as leading developmental interactions with the participants. The RP leverages through relationships creativity, the pursuit of autonomy, a greater understanding of yourself and can design changing attitudes. In conclusion RP is remarked for its methodology that promotes learning.

Keywords: Relational psychomotricity. Bioecology. Semiotim Mediation.

\section{RESUMEN \\ PSICOMOTRICIDAD RELACIONAL DESDE LA PERSPECTIVA DE LOS CONCEPTOS TEÓRICOS DE VYGOTSKY Y BRONFENBRENNER}

Este artículo tiene como objetivo presentar la psicomotricidad Relacional (PR) a través del diálogo entre la teoría socio-histórica de Lev Semionovitch Vygotsky y la teoría Bioecologica de Urie Bronfenbrenner. PR se basa en los aspectos lúdicos de jugar con el movimiento y la expresión artística/musical/verbal del cuerpo. Estos son los idiomas a través del cual los niños se manifiestan y comunican el establecimiento de puentes entre lo real y lo imaginario. Relaciones en PR será la nota clave del diálogo conceptual establecido entre los autores, haciendo hincapié en el poder de las diades en Bronfenbrenner y los procesos del mediación semiótica en Vygotsky. Mirar a través del prisma de estas dos teorías permite hacer hincapié en la importancia del papel de las interacciones de desarrollo psicomotor como empujador con los participantes. PR aprovecha a través de relaciones, la creatividad, la búsqueda de la autonomía, una mayor comprensión de sí mismo y puede diseñar a cambiar la actitud. De ello se deduce que PR es un diferencial con respecto a su potenciación metodología de nuevas aprendizaje.

Palabras clave: Psicomotricidad relacional. Bioecologia. Mediación semiótica.

\section{Introdução}

A Psicomotricidade Relacional (PR) tem por base a construção de possibilidades de aprendizagens por meio de uma sistemática dialógica. Negrine (1995), um dos precursores desta prática no Brasil, esclarece que se trata de uma abordagem que oportuniza uma atitude ativa dos participantes diante de possíveis conflitos internos, por meio de atividades lúdicas e jogos simbólicos, em um ambiente seguro e prazeroso, acompanhado por um psicomotricista. Aos participantes, a PR pode propiciar: o exercício do pensamento por intermédio do planejamento, elaboração e desenvolvimento de atividades concretas; a promoção da atenção, da verbalização e da escuta de si e dos demais colegas; oportunidades de vivências corporais concretas diversas e plurais; o comportamento cooperativo e agregador entre os participantes; a criatividade, o desenvolvimento e o planejamento de temas teatrais e da dança. 
Ademais, Negrine (1995) esclarece aos professores que se dedicam à Psicomotricidade Relacional na escola que esta estratégia pode auxiliar a desenvolver uma atitude de escuta e de ajuda à aprendizagem e desenvolvimento das crianças. Tal possibilidade se dá graças à disposição corporal que se ajusta à criança como forma de interação e intervenção em atividades lúdicas. Isso qualifica o processo de acompanhamento sistemático da evolução dos participantes nas sessões. Nesta perspectiva, o professor ou psicomotricista observa e acompanha a aprendizagem e o desenvolvimento do aluno durante as sessões, atuando no sentido de minimizar ou sanar os possíveis conflitos que a criança possa apresentar por meio de atividades lúdicas.

Nessa linha de elaborações, pode-se dizer que é imprescindível para a ida a campo o conhecimento do ambiente e a inserção do pesquisador onde ele irá atuar. 0 propósito é saber com quem estará atuando e quais as necessidades, carências, potencialidades, a fim de conhecer seu contexto ecológico. Cecconello e Koller (2004) denominam esse processo metodológico de Inserção Ecológica, metodologia que se aproxima da investigação qualitativa de cunho sócio-histórico. Conforme Freitas (2002), esta última também prevê uma aproximação ou uma imersão inicial no campo a ser investigado a fim de familiarizar-se com a situação e com os sujeitos a serem investigados. A inserção ecológica chama a atenção por poder ser uma fonte de diálogo metodológico entre os modelos ecológico e sócio-histórico dos autores em questão.

Bronfenbrenner (1996, p. 18), ao abordar o modelo Ecológico, refere-se a quatro sistemas conectados e articulados entre si: o primeiro é o microssistema que é definido como "um padrão de atividades, papéis e relações interpessoais experienciados pela pessoa em desenvolvimento, num dado ambiente com características físicas e materiais específicos". Esse autor exemplifica através de ambientes tais como: a casa, a creche ou a escola, nos quais a pessoa é envolvida em interações face a face. Os padrões de interação, conforme persistem e progridem por meio do tempo, constituem os veículos de mudança comportamental e de desenvolvimento pessoal. Igual importância é atribuída às interações entre as pessoas presentes no ambiente, à natureza desses vínculos relacionais e à sua influência direta e indireta sobre a pessoa em desenvolvimento (BRONFENBRENNER, 1996, p. 18).

O mesossistema refere-se a inter-relações entre dois ou mais ambientes nos quais uma pessoa participa ativamente, podendo ser constituído ou ampliado sempre que ela passa a fazer parte de novos ambientes. Em alguns casos, por exemplo, esse sistema inclui os sistemas das relações que uma criança mantém em casa, na escola, no clube e com amigos da vizinhança; em outros, apenas as relações exclusivamente familiares e com membros da igreja, clube etc. da qual sua família faz parte. A riqueza e a amplitude do mesossistema vai depender do número e da qualidade das interações nos microssistemas (YUNES; JULIANO, 2010). No terceiro contexto, exossistema, a pessoa em desenvolvimento não é participante ativa, mas, neste ambiente, podem ocorrer eventos que a afetem. Tais ambientes podem ser, para uma criança: o local de trabalho dos pais, a escola do irmão ou a rede de amigos dos pais.

E, por fim, para ter claro as interconexões entre os contextos sistêmicos, há o macrossistema, que envolve todos os outros ambientes, formando uma rede articulada (ou não) que interage e diferencia-se de uma cultura para outra. Para exemplificar questões macrossistêmicas, pode-se citar a estrutura política e cultural de uma família norte-americana de classe média, um sistema que difere enormemente de um grupo familiar de operários brasileiros. Diferenças e discrepâncias que se efetivam nas dimensões cultural, política, econômica e social. Aspectos que repercutem na qualidade de vida e no desenvolvimento das pessoas. 
Também é preciso esclarecer o que esse autor entende por desenvolvimento humano:

[...] mudança duradoura na maneira pela qual uma pessoa percebe e lida com o seu ambiente, [...] é o processo através do qual a pessoa desenvolvente adquire uma concepção mais ampliada, diferenciada e válida do meio ambiente ecológico, e se torna mais motivada e mais capaz de se envolver em atividades que revelam suas propriedades, sustentam ou restituíram aquele ambiente em níveis de complexidade semelhante ou maior de forma e conteúdo. (BRONFENBRENNER, 1996, p. 5).

O ambiente ecológico é entendido por Bronfenbrenner (1996) como um sistema de estruturas agrupadas, independentes e dinâmicas. O primeiro nível está relacionado ao efeito de influências proximais, ambientais e orgânicas que advêm do interior do indivíduo, de suas características físicas e de objetos do ambiente imediato, que caracterizam a relação face a face. Conforme já mencionado, este nível mais interno é chamado de microssistema e, no caso de nossa elaboração, refere-se à escola como ambiente de prática de PR.

Analisar a criança a partir do seu microssistema escola, mas considerando o impacto dos demais sistemas - meso, exo e macro -, é o que Bronfebrenner (1996) denomina de "olhar ecológico". Portanto, o educador deve "exercitar" e aguçar este olhar atento à trajetória lúdica da criança, ou seja, no que ela faz durante a sessão de PR, pois nestes momentos ela é autêntica, e revela seus conflitos, necessidades, carências. Este "olhar ecológico" é potente numa sessão de Psicomotricidade Relacional, permite fazer uma leitura do que ocorre no espaço e, a partir do comportamento e das interações da criança, fazer as intervenções e futuras propostas no intuito de promover sua aprendizagem e potencializar desenvolvimento biopsicossocial.

No que se refere a Vygotsky e sua obra, o pressuposto da mediação é conceito central (VYGOTSKY, 1996, 2000, 2001). Fato que o diferenciou dos demais psicólogos de sua época e da Psicologia tradicional. Ademais, esse pressuposto caracteriza a importância na construção e definição da abordagem sócio-histórica, pois é um norteador de todo o seu arcabouço teórico-metodológico. 0 ser humano se constitui nas relações sociais e em contextos sociais, econômicos, políticos, ambientais e culturais.

A mediação semiótica como pressuposto da relação Eu-Outro, como condição sine qua non da constituição do ser humano, explica os processos de apropriação, objetivação e subjetivação; assim como das relações constitutivas das funções psicológicas superiores ${ }^{1}$ a partir da superação das funções psicológicas inferiores. ${ }^{2}$ Além disso, potencializa as conexões e relações interfuncionais que acontecem na consciência, diferenciando os sujeitos.

Assim, a mediação semiótica é entendida como processo, porque não é o ato em que alguma coisa se interpõe. A mediação não está entre dois termos que estabelecem uma relação, mas é a própria relação. Conforme afirma Molon (2011), acontece por meio dos signos, das diferentes formas de semiotização, as quais possibilitam e sustentam as relações sociais, pois é um processo de significação que permite a comunicação entre as pessoas e a passagem da totalidade às partes e vice-versa.

Como já se afirmou,

A mediação não é a presença física do outro, não é a corporeidade do outro que estabelece a relação mediatizada, mas ela ocorre através dos signos, da palavra, da semiótica, dos instrumentos de mediação. A presença corpórea do outro não garante a mediação. Sem a mediação dos signos não há contato com a cultura. (MOLON, 2011, p. 102).

Essa noção de mediação semiótica é uma das maiores contribuições de Vygotsky, pois, ao conceber o fenômeno psicológico como

1 São operações psicológicas qualitativamente novas e mais elevadas, como a linguagem, a memória lógica, a atenção voluntária, a formação de conceitos, o pensamento verbal, a afetividade etc. (MOLON, 2011).

2 Caracterizam-se por serem imediatas, ou seja, reações diretas a uma determinada situação, porém matizadas afetivamente; são de origem natural e biológica, portanto são controladas pelo meio físico e social, consequentemente são inconscientes e involuntárias (MOLON, 2011). 
mediado, introduziu-se, no centro da análise psicológica, a atividade mediada por instrumentos e por signos, ou seja, a atividade do ser humano para mediar as suas relações com a natureza, com os outros e consigo mesmo.

Vygotsky (2003) apresenta uma teoria de desenvolvimento que reflete a criança em sua totalidade, articulando dialeticamente os aspectos internos e externos e considerando a relação dela com o contexto, história, sociedade e cultura na qual está inserida (FREITAS, 2002).

Vygotsky (1995) definiu as funções psicológicas superiores pela inter-relação com as funções psicológicas inferiores, sendo aquelas, porém, genética, estrutural e funcionalmente diferentes destas. A especificidade das funções psicológicas superiores é que elas são mediadas. Caracterizam-se por serem operações indiretas, que necessitam da presença de um signo mediador, sendo a linguagem o principal sistema signo. Todas as funções psicológicas superiores originam-se das relações entre os indivíduos. As relações não são inventadas nem aparecem de forma repentina, e não são funções a priori, ou seja, não existem independentemente das experiências. São funções que apresentam uma natureza histórica e, como são de origem sociocultural, são mediadas.

Tais perspectivas das abordagens teóricas em questão devem ser uma constante nas sessões de PR, uma vez que as crianças adotam condutas, posturas e comportamentos de acordo com o momento histórico e o papel social que assumem em determinada atividade. Exemplificando: a criança, ao brincar de bombeiro, policial, professor ou de mamãe, vai agir de acordo com o que observa e a vivência em seu contexto imediato. Sob a perspectiva ecológica de Bronfenbrenner, isso advém de seu microcontexto ou microssistema. Este é influenciado pelos demais contextos, inclusive pela cultura do macrocontexto ou macrossistema. E, sob o ângulo da abordagem sócio -histórica, a criança, através da relação com os outros por meio da mediação semiótica, constitui suas funções psicológicas superiores, isto é, desenvolve a linguagem, o pensamento, o raciocínio, a memória e a afetividade. Desse modo, a criança se desenvolve nas vivências com os outros em um ambiente específico, no qual ocorrem as interações, as observações, a imitação, o jogo de faz de conta, os quais potencializam o seu aprendizado.

\section{Psicomotricidade Relacional: conceitos e pressupostos teóricos}

A Psicomotricidade Relacional teve seu início na França. Os precursores desta prática foram os psicomotricistas André Lapierre (2010) e Bernard Aucouturier, Ivan Darrault e Jean-Louis Empinet (1986) e, mais tarde, foi introduzida em outros países, inclusive no Brasil. Atualmente, há vários autores voltados para o estudo e a pesquisa da PR que trazem vários conceitos que se relacionam e confundem. Adotar-se-á neste texto a seguinte compreensão: PR caracteriza-se por escutar, considerar e notabilizar o diálogo entre os aspectos corporais e os psíquicos do ser humano, focalizando a compreensão e a atividade dos núcleos psicoafetivos e seus decorrentes elementos relacionais interpessoais, oferecendo um espaço de jogo espontâneo que incentiva e facilita a manifestação e expressão de dificuldades relacionais. Focaliza, ainda, necessidades e desejos, potencializando a socialização através de uma decodificação simbólica do comportamento natural e descontraído do sujeito, por uma leitura de conteúdo comunicativo-simbólico, que intervém na estruturação e evolução da dimensão afetiva (AUCOUTURIER; DARRAULT; EMPINET 1986; LAPIERRE, 2010; LAPIERRE; AUCOUTURIER, 1984).

Um dos aspectos fundamentais apontados pelos precursores da proposta é a relação estabelecida entre os participantes e destes com os objetos. Outro elemento imprescindível é a mediação do psicomotricista durante as sessões. Neste aspecto, pode-se citar que 
as ideias de Vygotsky e de Bronfenbrenner autenticam os princípios da PR. A teoria de Vygostky acentua que as construções da criança com o meio e os objetos só terão sentido se houver o outro humano (SIRGADO, 2000), e a de Bronfenbrenner apresenta os processos proximais como interações humanas significativas e motores de desenvolvimento e aprendizagens (MACHADO; YUNES; SILVA, 2014). Desta forma, o mediador definirá a qualidade de desenvolvimento da criança e a condução das sessões é que poderá permitir o desenvolvimento dos participantes.

O conceito de processos proximais de Bronfenbrenner e Morris (1998) pode se justapor à construção do conceito de zona de desenvolvimento proximal de Vygotsky (1984). Esses autores concebem o desenvolvimento e a aprendizagem humana como processos inter -relacionados, dependentes reciprocamente um do outro. Rompem com a ideia bastante difundida por alguns autores tradicionais da Psicologia de que o desenvolvimento é independente da aprendizagem e de que o desenvolvimento é sempre um pré-requisito para a aprendizagem. Ou seja, é necessário o pré-requisito da maturidade do desenvolvimento para realizar a aprendizagem.

Aprendizagem e desenvolvimento estão inter-relacionados durante toda a vida: o aprendizado promove desenvolvimento e o desenvolver-se gera novas aprendizagens. Desse modo, Vygotsky (1984) é contrário ao estabelecimento de etapas, cronologias e estágios de desenvolvimento. Ele acredita que existem dois níveis de desenvolvimento: o nível de desenvolvimento real, que é aquele que a criança apresenta como já conquistado e consegue fazer sem ajuda (sozinha), e o nível de desenvolvimento potencial, que é aquele que ela realiza com a orientação de um outro sujeito, ou seja, aquilo que ainda não é capaz de conseguir sozinha. A Zona de Desenvolvimento Proximal é a distância entre estes níveis.

A potencialidade desses conceitos permite que o sujeito seja visto na sua complexidade, nos diversos aspectos que o constitui, nas diferentes relações colaborativas e significativas estabelecidas e nos variados contextos educativos em que participa (BERSCH; PISKE, 2020). Assim, busca-se compreender o ser humano de modo integral no conjunto das relações e práticas pedagógicas e educativas, valorizando as práticas significativas e as aprendizagens colaborativas. Tais aprendizagens exigem a participação criadora dos sujeitos na resolução dos problemas, na tomada de iniciativa, na apropriação de novos conceitos e novas habilidades no processo de ensino-aprendizagem.

Estudiosos da metodologia, como Vitor da Fonseca (2004, p. 12), afirmam que:

A psicomotricidade constitui uma abordagem multidisciplinar do corpo e da motricidade humana. Seu objeto é o sujeito humano total e suas relações com o corpo, sejam elas integradoras, emocionais, simbólicas ou cognitivas, propondose desenvolver faculdades expressivas do sujeito, nas quais, por esse contexto, assume uma dimensão educacional e terapêutica original, com objetivos e meio próprios que se destacam de outras abordagens.

0 educador que adota a metodologia da Psicomotricidade Relacional promove uma atitude de escuta e de ajuda à aprendizagem e desenvolvimento dos alunos, em virtude da disposição corporal que se ajusta ao educando como forma de interação e intervenção em atividades lúdicas (NEGRINE, 1995). Isso qualifica o processo de acompanhamento sistemático da evolução das crianças no decorrer das sessões. O educador observa e acompanha a aprendizagem e o desenvolvimento do aluno durante as sessões e tem a responsabilidade de atuar a fim de minimizar ou sanar os possíveis conflitos que a criança possa demonstrar por meio das atividades lúdicas propostas.

Oportunizar a escuta, considerar e potencializar o diálogo entre o corpo e os aspectos psíquicos do ser humano, focalizar na compreensão e na atividade dos núcleos psicoafetivos são elementos constitutivos da Psicomotricidade Relacional. A PR propicia um espaço de jogo espontâneo e lúdico, o 
que favorece o incentivo e facilita a criança a manifestar e expressar suas dificuldades relacionais, suas necessidades e seus desejos. Situação que potencializa a socialização por intermédio de uma decodificação simbólica do comportamento natural e descontraído do participante, por meio de uma leitura de seu conteúdo comunicativo-simbólico, a fim de intervir na estruturação e evolução da dimensão afetiva (AUCOUTURIER et al., 1986; LAPIERRE; LAPIERRE, 2010; OLIVEIRA, 2014).

A prática psicomotriz educativa tem como eixo três alicerces, que são: a comunicação, a exploração corporal e as vivências simbólicas, caracterizadas com o favorecimento do movimento espontâneo da criança e a estrutura das aulas, que facilita a comunicação e a interação dos participantes (NEGRINE, 1995; LAPIERRE; LAPIERRE, 2010). Uma das vantagens desta prática psicomotriz pedagógica é a interação do educador como facilitador no desenvolvimento dos envolvidos na proposta. Visto que a Psicomotricidade Relacional é organizada em estruturas e rotinas claras que facilitam ao professor o planejamento e a elaboração das atividades e estratégias para cada criança e, ao mesmo tempo, para o coletivo, por intermédio de diferentes materiais que favorecem a evolução do comportamento dos participantes dentro de um ambiente seguro (LAPIERRE; AUCOUTURIER, 1984).

Percebe-se, portanto, o ambiente escolar como um lugar de mediações, interações e evoluções. A atuação do professor no ambiente escolar, por meio da estratégia pedagógica Psicomotricidade Relacional, é uma consistente possibilidade de educar pelas relações num espaço enriquecido por símbolos e objetos, numa inter-relação dos sujeitos com eles mesmos, com o outro e com o próprio ambiente. Lembramos que o ambiente ecológico de desenvolvimento humano, conforme nos ensina Bronfenbrenner (1996), é um processo de acomodação mútuo, no qual a interação da criança com o meio ambiente é bidirecional, pautada pela reciprocidade, incluindo interconexões entre esses ambientes. Portanto, não se limita apenas a um ambiente único e imediato, e deve ser "concebido topologicamente como uma organização de estruturas concêntricas, cada uma contida na seguinte" (BRONFENBRENNER, 1996, p. 18).

\section{Metodologia das sessões de Psicomotricidade Relacional}

Planejamento prévio é fundamental para que o psicomotricista realize um trabalho que considere elementos de espaço, tempo, material e as estratégias adequadas à faixa etária a ser atendida. Portanto, cada sessão de PR deve ter uma preparação, com dedicação e responsabilidade para garantir a qualidade e segurança dos envolvidos.

Quanto ao espaço, é importante prever um ambiente considerando a faixa etária e o número dos participantes. Vieira, Batista e Lapierre (2005) afirmam que o espaço deve permitir a movimentação e deslocamentos para as atividades corporais dos participantes; o uso de materiais diversos proporciona novas emoções e vivências à criança, tornando mais rico e variado seu jogo sensório-motor e simbólico. Múltiplos objetivos e atividades também favorecem a liberdade de expressão e o desenvolvimento da criatividade.

Nas sessões de PR, o corpo é o principal fio condutor da prática. $O$ corpo do outro que brinca numa relação de parceria torna-se meio de interação, sendo este composto por múltiplas relações: perceptivas, imaginárias e simbólicas, favorecendo de maneira dinâmica o ato ao sentimento, ao pensamento, ao gesto, à palavra, e o símbolo ao conceito (VIEIRA; BATISTA; LAPIERRE, 2005, p. 14). 0 participante de sessões de psicomotricidade não encontra modelos de brincar ou brinquedos pré-estabelecidos, o que garante o seu protagonismo na ação.

Diferentemente das aulas dirigidas e com movimentos, jogos e brinquedos pré-estabelecidos, nas sessões de PR o improvável muitas 
vezes acontece, possibilitando uma maior riqueza de experiências, pois cada aluno traz uma bagagem de conhecimentos adquiridos no meio e na cultura em que vive. A PR é entendida como o jogo/brincar que a criança realiza no dia a dia incorporado como componente pedagógico, estabelecendo o lúdico como facilitador das inter-relações pessoais. Dentro desse marco relacional, o mais importante é trabalhar com o que a criança tem de positivo, com o que ela sabe fazer, e não se preocupar com o que ela não sabe. Negrine (1994a, 1994b) defende que o melhor método para ajudar uma criança a superar suas dificuldades é conseguir que ela esqueça suas inabilidades. Atualmente, um movimento na psicologia intitulado Psicologia Positiva (POSECK, 2008) vem tomando corpo desde 1998 com ideias que sugerem desfocar sintomas para focar forças e virtudes, reforçando, ainda, propostas de intervenções positivas e protetoras (SELIGMAN et al., 2005).

Vygotsky (1984), além de elaborar o conceito de zona de desenvolvimento proximal, chamando a atenção para a Educação prospectiva, sempre defendeu a ideia de que o sujeito deve ser considerado na sua totalidade e não apenas na sua deficiência. Para ele, não é a deficiência que define o sujeito, mas é o sujeito que define sua deficiência na relação com os outros e consigo mesmo. Assim, a zona de desenvolvimento proximal se estabelece numa relação dialética entre o eu e o outro que ocorre por meio das mediações semióticas, condição de existência da comunicação e do intercâmbio entre os sujeitos. Desta forma, o sujeito relacional capaz de afetar outros corpos e ser por eles afetado é visto como um acontecimento com um outro, provocado pela mediação desse outro, em um processo sócio-histórico e cultural.

A Psicomotricidade Relacional oportuniza uma atitude ativa dos participantes por meio do envolvimento em jogos simbólicos. Nas relações e interações o corpo encontra um espaço privilegiado, pois a ele é oportunizado a comunicação e a manifestação das emoções.
No espaço da PR a criança se sente em um ambiente seguro e prazeroso, uma vez que é mediado pelo professor (BERSCH; JULIANO, 2016; JULIANO et al., 2016). Tanto para a teoria Bioecológica de Bronfenbrenner, como para a teoria Sócio-Histórica de Vygotsky o importante é a mediação. Esses autores defendem a importância de um mediador nas interações e nas relações estabelecidas entre duas ou mais pessoas como potência ou motores dos processos de desenvolvimento e aprendizagem.

Portanto, o diferencial da prática psicomotriz pedagógica se situa na interação do adulto como facilitador do desenvolvimento das crianças participantes envolvidas, sendo organizada a PR com estruturas de rotina, ajudando, assim, o educador na elaboração das atividades e estratégias com o auxílio de diferentes materiais a fim de favorecer a evolução no comportamento dos participantes (NEGRINE, 1995).

A Psicomotricidade Relacional potencializa a criatividade por meio da interação com os colegas e manipulação de objetos não estereotipados. Materiais que são objetos simples como, por exemplo, cordas, colchonetes, tecidos, caixas, arcos, jornais, tampinhas etc., e que podem ser explorados pelos envolvidos, oferecendo uma infinidade de possibilidades de jogos sensório-motor e simbólico. Este ponto está ancorado nos conceitos das duas teorias discutidas neste artigo, que são: as díades relacionais/processos proximais (BRONFENBRENNER, 1996, 2011) e a mediação semiótica (VYGOTSKY,1996).

A PR se organiza com momentos sistematizados que são: rito de entrada, sessão propriamente dita, volta à calma, registro e rito de saída. A seguir, com base nos estudos de Negrine (1995), serão descritos estes passos:

1. Rito de entrada: são feitas as combinações para favorecer a comunicação entre as crianças e o educador. Nesta etapa, os participantes aprendem a criar regras de convivência e expressá-las verbalmente, respeitando seu espaço e o dos colegas. 
2. Sessão propriamente dita: o professor tem um papel extremamente importante como facilitador, sugerindo, desafiando e provocando a postura lúdica dos envolvidos. É importante estar em situação de escuta para compreender o desenvolvimento das crianças ao longo do processo. 0 facilitador varia os materiais a serem disponibilizados e disponibiliza quantidade adequada à interação de todos os envolvidos na sessão.

3. Volta à calma: neste momento o psicomotricista oportuniza aos envolvidos momentos de relaxamento para baixar a frequência cardíaca.

4. Registro: por meio de várias técnicas, intenta-se que os participantes registrem sentimentos e emoções vivenciadas no decorrer da sessão. Tão importante quanto o desenho, pintura, gesto ou outra forma de registro da criança é procurar estratégias para compreender estes registros e contrapô-los com as falas no rito de saída.

5. Rito de saída: oportuniza que os participantes comentem sobre suas criações nos jogos e exercícios, sendo fundamental o processo de escuta para o princípio da prática psicomotriz pedagógica educativa. Geralmente se usa um objeto demarcando a vez de quem realizará o relato, facilitando a compreensão de quando será a vez de cada criança falar. Este procedimento visa diminuir a ansiedade dos participantes.

A escuta atenta e os registros por parte do professor são fundamentais para acompanhar a evolução dos participantes, bem como para o planejamento da sessão seguinte. Identificar por meio da observação das ações e interações no decorrer da trajetória lúdica, bem como em seus relatos, as dificuldades e as potencialidades de cada criança promoverão a qualificação do processo de aprendizagem e desenvolvimento do participante (BERSCH; PISKE, 2020).

\section{As interfaces da Psicomotricidade Relacional com as teorias de Vygotsky e Bronfenbrenner}

Os aspectos da Psicomotricidade Relacional, como as mediações, interrelações, elaborações e construções das crianças participantes, potencializam as suas subjetividades no decorrer da trajetória lúdica. 0 componente lúdico presente nas sessões de PR oportuniza as relações e interações, as quais são promotoras do desenvolvimento e da aprendizagem. 0 movimento, outro aspecto inerente à criança, também facilita as expressões por via da linguagem corporal no momento do brincar e possibilita a manifestação das emoções. Analisar tais percepções e concepções a partir de dois teóricos - Vygostsky e Bonfenbrenner - permite lançar luz às interfaces da PR ao estabelecer diálogo entre os processos de mediação semiótica e as díades propostas por esses estudiosos.

A linguagem utilizada durante as brincadeiras é motivo de atenção durante as sessões de PR. Quanto a isso, é importante lembrar Vygotsky (2001), que afirma que o significado das palavras traz um sentido atribuído que não é imutável, pois outro sentido para a mesma palavra pode ser construído de acordo com a cultura em que o sujeito está inserido (ZANELLA et al., 2007). Para este autor, o pensamento se realiza na palavra, que ganha significado pelo pensamento. "O pensamento não apenas se expressa na palavra, mas nela se realiza." (VYGOTSKY, 1996, p. 182). O pensamento passa a existir através da palavra, mas, para isso, atravessa diversas transformações, pois a fala não é cópia do pensamento. Dessa forma, a linguagem e o pensamento são orientados por questões diferentes, impossibilitando a transição direta do pensamento para a fala.

Nessa perspectiva, não existe uma relação direta entre o pensamento e a linguagem, por isso a fala não é o pensamento verbalizado como afirmam outras teorias clássicas da 
Psicologia. Portanto, é fundamental encontrar o significado das palavras, é por meio desse significado que o pensamento se realiza e se objetiva, ganha vida, materialidade e visualidade. Por isso, é necessário que o pensamento se realize nas palavras, que as palavras sejam compreendidas nos seus significados e múltiplos sentidos, para que os pensamentos deixem de ser sombras e as palavras, sons vazios. Assim, podemos reconhecer, como diz Vygotsky (2001), que é a base afetivo-volitiva, isto é, os sentimentos, a vontade, o desejo e as necessidades, que move os pensamentos humanos.

Para Vygotsky, "o sentido da palavra é a soma de todos os eventos psicológicos evocados em nossa consciência graças à palavra. 0 significado é só uma dessas zonas de sentido, a mais estável, coerente e precisa" (ZANELLA et al., 2007). O sentido de uma palavra modificase tanto dependendo das situações como das pessoas que o atribuem; por isso, é considerado quase ilimitado. Entretanto, os processos de significação, significados e sentidos são produzidos e apropriados nas relações sociais.

Nesse aspecto, Vygotsky e Bronfenbrenner convergem, visto que ambos entendem que tanto os significados e os sentidos, como os comportamentos são construídos pela pessoa em suas relações considerando sua trajetória, vivências e experiências dentro de um contexto social e cultural. De acordo com Bronfenbrenner (1996), esse contexto estará sempre imerso na interconexão dos quatro contextos mencionados e descritos aqui: micro, meso, exo e macrosistema. Os dois autores concordam com a importância do elemento tempo (BRONFENBRENNER; MORRIS, 1998) e com o aspecto histórico (VYGOTSKY, 2000) na vida das pessoas.

Além disso, a PR favorece as relações entre criança e professor ou psicomotricista, relações denominadas por Bronfenbrenner (1996) como díades que evoluem de observacionais para primárias. Esse autor esclarece que ocorre uma díade "sempre que uma pessoa em um ambiente presta atenção às atividades de uma outra pessoa, ou delas participa, existe uma relação" (BRONFENBRENNER, 1996, p. 46).

A díade, explica Bronfenbrenner (1996), é importante, em especial, por dois aspectos: ela constitui um contexto crítico para o desenvolvimento e serve como um bloco construtor básico do microssistema que potencializa a formação de estruturas interpessoais maiores - tríades, tétrades e assim por diante.

Para que as díades tenham um poder desenvolvimental e se justifiquem, devem ter certas propriedades que são comuns a todas as díades. Segundo Bronfenbrenner (1996), as propriedades são: reciprocidade, equilíbrio de poder e afetividade. Portanto, a estratégia de intervenção Psicomotricidade Relacional possibilita ao educador um olhar sensível e uma prática pedagógica através da via corporal, o que permite uma maior ludicidade aos participantes num relacionar-se, dialogar, perceber, sentir, o que motiva os participantes e o educador, numa relação de reciprocidade.

No modelo ecológico, Bronfenbrenner (1996) se debruçou a investigar a pessoa em desenvolvimento e focalizou as constantes interações com os ambientes proximais e as relações estabelecidas entre os contextos mais distais. Contudo, numa análise mais profunda, ele constatou que era necessário um olhar cuidadoso e detalhado para as características biopsicológicas da pessoa em desenvolvimento, o que deu origem ao modelo Bioecológico (BRONFENBRENNER; MORRIS, 1998). A partir deste modelo, o termo desenvolvimento é reconfigurado: "desenvolvimento refere-se à estabilidade e mudança nas características biopsicológicas dos seres humanos durante o ciclo de suas vidas e através das gerações" (BRONFENBRENNER; MORRIS, 1998, p. 995).

A partir desta nova ótica, Urie Bronfenbrenner e Pámela Morris apresentaram um construto-chave denominado processo proximal (BRONFENBRENNER; MORRIS, 1998). Os processos proximais são definidos como motores do desenvolvimento e, para que se efetivem, é necessário que a pessoa esteja inserida em 
uma atividade; esta interação deve acontecer efetiva, regular e reciprocamente, através de períodos prolongados de tempo; a atividade deve ainda ser progressivamente mais complexa; e os objetos e símbolos presentes no ambiente imediato devem estimular a atenção, a exploração, a manipulação e a imaginação da pessoa em desenvolvimento (NARVAZ; KOLLER, 2004; YUNES; JULIANO, 2010).

Portanto, os processos proximais podem ser potencializadores do desenvolvimento, mas é preciso estar atento e observar as formas de interação da pessoa em desenvolvimento com os seus pares, com símbolos e objetos que constituem o(s) espaço(s) no(s) qual(is) ela se encontra. Nesse movimento, é fundamental compreender as complexidades das interações diádicas - triádicas e intrafamiliares -, mas também olhar com cuidado e com a mesma intensidade as interações com outras pessoas em seus diferentes aspectos concretos e simbólicos que representam a rede de apoio social (YUNES; JULIANO, 2010).

\section{Considerações finais}

A intenção deste artigo foi promover um diálogo entre dois autores relevantes na compreensão da PR como promotora de desenvolvimento e de aprendizagem. Não houve a intenção de priorizar um em detrimento de outro, mas buscou-se apontar os conceitos das teorias como significativas e suas aproximações e complementariedades para sustentação de algumas das práticas e procedimentos da PR.

Na elaboração das reflexões de similitudes e complementariedades das duas teorias, encontram-se alguns conceitos, tais como: mediação, mediação semiótica, relação afetiva, base afetivo-volitiva, díade primária. Vygotsky traz como contribuição para esta reflexão a mediação semiótica. "Se a mediação técnica permite ao homem transformar (dar uma nova forma) à natureza da qual ele é parte integrante, é a mediação semiótica que lhe permite conferir a esta nova forma uma significação." (SIRGADO, 2000 , p. 55). A mediação semiótica está presente nas relações humanas, que faz acontecer as conexões que são estabelecidas entre os pares mesmo sem a presença física do outro, característica da díade primária postulada por Bronfenbrenner (1996). A díade primária é possibilitada pela base afetivo-volitiva que Vygotsky (2001) postulou e é compreendida pelos sentimentos, pela vontade, pelo desejo e pelas necessidades que movem os pensamentos humanos. Os dois autores defendem a importância das relações e interações no desenvolvimento e na aprendizagem, destacando a vivência simbólica.

Nesse sentido, a criança, no processo de tornar-se um adulto, terá obrigatoriamente que relacionar-se, interagir e comunicar-se com outros seres humanos da sociedade por meio da mediação semiótica, que é um sistema complexo (SIRGADO, 2000).

Conforme demonstrado, a PR potencializa a criatividade, a busca da autonomia, uma compreensão maior de si mesmo e pode projetar mudança de atitudes. Neste processo de subsídio relacional, o ser humano é entendido em sua totalidade e por intermédio de expressões através do movimento, que traduz emoções, sentimentos que advêm de conflitos e necessidades internas. Na relação com o outro, promove-se a descoberta de potencialidades, muitas vezes, não reveladas até então. Considerando que o movimento é inerente às crianças, a PR representa um diferencial no que se refere à metodologia e como propulsor de aprendizagem.

Ao participarem das sessões de PR, as crianças podem vivenciar experiências corporais diversas e com múltiplos objetos. Ao serem auxiliadas por seus pares e pelo psicomotricista, aprendem modelos novos, ampliando seu vocabulário motriz, além de provocar o simbolismo e a necessidade de comunicação entre os participantes. Considerando que a aquisição dos processos mentais superiores ocorre pela interação com o meio, as vivências 
lúdicas podem ser provocadoras de novas zonas proximais (VYGOTSKY, 1984). Assim, a PR que utiliza o movimento e a ludicidade no processo pedagógico torna-se um ambiente favorável e propício para a amplificação e o aprimoramento da aprendizagem.

Nessa perspectiva, pode-se refletir sobre a PR e a potencialização dos processos proximais promotores da linguagem, do pensamento e de outras aprendizagens. 0 lúdico é o componente humano que amplia as possibilidades de criatividade, de investigação, de curiosidade, de descoberta, de inter-relações e é elemento fundamental nas sessões de PR. 0 psicomotricista, portanto, deve estar atento para promover as mediações e os processos proximais no decorrer dos encontros da PR: envolver as crianças em atividades ora individuais ora coletivas, agregadoras e de jogos cooperativos; estabelecer interrelações entre os participantes; propiciar atividades, brincadeiras, jogos, movimentos progressivamente mais complexos; oferecer objetos alternativos que possam estimular a imaginação, criatividade, inventividade e atenção dos participantes.

Como Vygotsky e Bronfenbrenner nos ensinam, as aprendizagens provocadas numa sessão de PR não irão ocorrer somente nas sessões ou no ambiente em que esta estiver acontecendo, mas também após o encerramento dela, visto que as aprendizagens ocorrem a partir das interações com o meio externo e entre as pessoas, de forma interpsíquica mas também intrapsíquica. Esta última pode ocorrer depois das sessões. Explicando de outra forma, podemos tomar como exemplo um jogo ou uma brincadeira da qual a criança tenha participado durante uma sessão. As emoções provocadas a partir das interações com o outro ou com o objeto podem fazer parte do pensamento desta criança por muito tempo. Este é o elemento construtor dos processos proximais, das díades, da mediação e da mediação semiótica.

0 psicomotricista deve olhar com cuidado para a atividade das crianças e não enxergar apenas o movimento, mas olhar para as expressões imbuídas de simbolismo, que podem ser manifestadas por desejos, conflitos, representações etc., presentes no imaginário dos participantes. A dinâmica da PR consiste em propiciar um espaço, objetos e movimentos corporais às crianças com o intuito que esta exteriorize desejos, carências, solucione possíveis conflitos, estabeleça confrontos com a realidade. E o papel do psicomotricista é de acompanhar a trajetória lúdica da criança, oferecendo diversos objetivos, materiais, desafiar, provocando um jogo simbólico, sempre com uma postura de escuta e de olhar para as demandas dos participantes.

A Psicomotricidade Relacional privilegia o brincar livre e espontâneo. Fato que oportuniza muitos participantes a manifestarem diversos sentimentos e emoções por meio da ludicidade e do brincar: a agressividade, a inventividade, a criatividade, a afetividade e outros aspectos inerentes ao desenvolvimento psicomotor. Nesta ótica, percebemos a capacidade criativa e interativa das crianças com materiais não estereotipados que potencializam o imaginário delas, salutar para o desenvolvimento.

Essa proposta oferece às crianças ricos momentos e vivências diversas, tornando-as ativas frente a situações de conflito e possibilitando ações sobre os possíveis prejuízos que possam acarretar. Neste sentido, as atividades lúdicas e jogos simbólicos podem significar uma condição de proteção e favorecer aprendizagens significativas e melhores condições de desenvolvimento biopsicossocial. "Olhar" esta metodologia sob a ótica da teoria de Bronfenbrenner e de Vygotsky permite-nos a confirmação da importância do professor, mediador ou do psicomotricista que orienta, acompanha e potencializa as mediações da criança com o profissional, com ela mesma, com seus pares e com os objetos. E, sobretudo, permite inferir que a Psicomotricidade Relacional pode ser promotora de desenvolvimento e de múltiplas aprendizagens. 


\section{REFERÊNCIAS}

AUCOUTURIER, B.; DARRAULT, I.; EMPINET, J. L. A prática psicomotora: reeducação e terapia. Porto Alegre: Artes Médicas, 1986.

BERSCH, A. A. S.; PISKE, E. L. Psicomotricidade relacional: estratégia de intervenção pedagógica na educação. Itinerarius Reflectionis, v. 16, n. 3, p. 1-18, abr. 2020. Disponível em: https://www. revistas.ufg.br/rir/article/view/60420. Acesso em: 15 jun. 2020.

BERSCH, A. A. S.; JULIANO, A. Psicomotricidade relacional e a repercussão na formação acadêmica de alunos de Educação Física - FURG. Revista Didática Sistêmica, v. 17, n. 1, p. 121-134, 2016. Disponível em: https://periodicos.furg.br/redsis/ article/view/5906. Acesso em: 18 jul. 2020.

BRONFENBRENNER, U. A ecologia do desenvolvimento humano: experimentos naturais e planejados. Porto Alegre, Artes Médicas, 1996.

BRONFENBRENNER, U. Bioecologia do desenvolvimento humano: tornando seres humanos mais humanos. Porto Alegre: Artmed, 2011.

BRONFENBRENNER, U.; MORRIS, P. A. The ecology of developmental process. In: DAMON, W.; LERNER, R. M. (ed.). Handbook of child psychology: theoretical models of human development. 5. ed. New York: John Wiley \& Sons, 1998. p. 993-1028.

CECCONELLO, A. M.; KOLLER, S. Inserção ecológica na comunidade: uma proposta metodológica para o estudo de famílias em situação de risco. In: KOLLER, S. H. (ed.). Ecologia do desenvolvimento humano: pesquisa e intervenção no Brasil. São Paulo: Casa do Psicólogo, 2004. p. 267-291.

FREITAS, M. T. A. A abordagem sócio-histórica como orientadora da pesquisa qualitativa. Cadernos de Pesquisa, São Paulo, n. 116, p. 21-39, jul. 2002.

FONSECA, V. da. Psicomotricidade: perspectivas multidisciplinares. 1. ed. Porto Alegre: Artmed, 2004.

JULIANO, A. Et al. Psicomotricidade relacional na educação infantil: relações de pertencimento e reflexões com a educação ambiental. REMEA Revista Eletrônica do Mestrado em Educação Ambiental, v. 33, n. 3, p. 198-212, 2016. Disponível em: https://periodicos.furg.br/remea/article/ view/5832. Acesso em: 21 ago. 2020

LAPIERRE, A. Da psicomotricidade relacional à analise corporal da relação. Curitiba: Ed. UFPR, 2010.

LAPIERRE, A.; AUCOUTURIER, B. Fantasmas corporais e prática psicomotora. São Paulo: Manole, 1984.

LAPIERRE, A.; LAPIERRE, A. 0 adulto diante da criança de 0 a 3 anos: psicomotricidade relacional e formação da personalidade. Curitiba: Ed. UFPR: Criar, 2010.

MACHADO, J. A.; YUNES, M. A. M.; SILVA, G. F. A formação continuada de professores em serviço na perspectiva da abordagem ecológica do desenvolvimento humano. Contrapontos, v. 14, n. 3, p. 512-526, 2014. Disponível em: http://www6. univali.br/seer/index.php/rc/article/view/4842. Acesso em: 28 fev. 2015.

MOLON, S. I. Subjetividade e constituição do sujeito em Vygotsky. Petrópolis, RJ: Vozes, 2011.

NARVAZ, M.; KOLLER, S. H. Famílias, violências e gêneros: desvelando as tramas da transmissão transgeracional da violência de gênero. In: STREY, M. N.; AZAMBUJA, M. P. R.; JAEGER, F. P. (eds.). Violência, gênero e políticas públicas. Porto Alegre: EDIPUCRS, 2004. p. 149-176.

NEGRINE, A. Aprendizagem e desenvolvimento infantil - simbologia e jogo. Porto Alegre: Prodil, 1994a.

NEGRINE, A. Aprendizagem e desenvolvimento infantil - perspectiva psicopedagógicas. Porto Alegre: Prodil, 1994b.

NEGRINE, A. Aprendizagem e desenvolvimento infantil - psicomotricidade: alternativas pedagógicas. Porto Alegre: Prodil, 1995.

OLIVEIRA, L. 0 sentido do lugar. In: MARANDOLA JUNIOR, Eduardo; HOLZER, Werther; OLIVEIRA, Lívia de. Qual o espaço do lugar? 1. ed. São Paulo: Perspectiva, 2014.

POSECK, B. V. Psicología positiva: una nueva forma de entender la psicología. Madrid: Calamar Ediciones, 2008.

SELIGMAN, M. E. P. Et al. Positive psychology progress: empirical validation of interventions. American Psychologist, v. 60, n. 5, p. 410-421, 2005.

SIRGADO, A. P. O social e o cultural na obra de Vigotsky. Educação \& Sociedade, ano XXI, v. 21, n. 
71, p. 45-78, jul. 2000. Disponível em: http://www. scielo.br/pdf/es/v21n71/a03v2171.pdf. Acesso em: 23 abr. 2020.

VIEIRA, J. L.; BATISTA, M. I. B.; LAPIERRE, A. Psicomotricidade relacional: a teoria de uma prática. Curitiba: Filosofart, 2005.

VYGOTSKY, L. S. A formação social da mente. São Paulo: Martins Fontes, 1984.

VYGOTSKY, L. S. Historia del desarrollo de las funciones psíquicas superiores. Madrid: Visor Distribuciones S.A., 1995.

VYGOTSKY, L. S. Teoria e método em psicologia. São Paulo: Martins Fontes, 1996.

VYGOTSKY, L. S. Manuscrito de 1929. Educação \& Sociedade, v. 21, n. 71, p. 21-44, 2000.

VYGOTSKY, L. S. A construção do pensamento e da linguagem. São Paulo: Martins Fontes, 2001.
VYGOTSKY, L. S. 0 desenvolvimento psicológico na infância. São Paulo: Martins Fontes, 2003.

ZANELLA, A. Etal. Questões de método em textos de Vygotski: contribuições à pesquisa em Psicologia. Psicologia \& Sociedade, v. 19, n. 2, p. 25-33, 2007. Disponível em: http://www.scielo.br/pdf/psoc/ v19n2/a04v19n2.pdf. Acesso em: 20 abr.2020

YUNES, Maria A. M.; JULIANO, Maria C. A bioecologia do desenvolvimento humano e suas interfaces com educação ambiental. Cadernos de Educação, Pelotas, RS, n. 37, p. 347-379, set./ dez. 2010. Disponível em: https://periodicos. ufpel.edu.br/ojs2/index.php/caduc/article/ viewFile/1591/1477. Acesso em: 20 ago. 2020.

Recebido em: 27/04/2020 Revisado em: 19/12/2020 Aprovado em: 22/12/2020 